\title{
Weakening of nurses practice delivering same day-access in primary care
}

\author{
Fragilização da prática do enfermeiro no atendimento à \\ demanda espontânea na atenção primária \\ Fragilización de práctica de la enfermería a consulta a \\ demanda espontánea en atención primaria
}

\section{Gláucia Bohuscha \\ Sonia Aciolib \\ Ricardo de Mattos Russo Rafael ${ }^{\mathrm{b}}$ \\ Alex Simões de Mellob \\ Juliana Roza' \\ Halene Cristina de Armada e Silva ${ }^{d}$}

\section{How to cite this article:}

Bohusch G, Acioli S, Rafael RMR, Mello

AS, Roza J, Silva HCA. Weakening of nurses practice delivering same day-access in primary care. Rev Gaúcha Enferm. 2021;42:e20200314. doi: https://doi org/10.1590/1983-1447.2021.20200314

\footnotetext{
aniversidade Federal de Santa Catarina (UFSC) Colégio de Aplicação. Florianópolis, Santa Catarina, Brasil.

- Universidade do Estado do Rio de Janeiro (UERJ), Faculdade de Enfermagem, Departamento de Enfermagem em Saúde Pública. Rio de Janeiro, Rio de Janeiro, Brasil.

" Universidade Federal do Rio de Janeiro (UFRJ), Escola de Enfermagem Anna Nery, Departamento de Enfermagem de Saúde Pública. Rio de Janeiro, Rio de Janeiro, Brasil.

a Secretaria Municipal de Saúde (SMS). Rio de Janeiro, Rio de Janeiro, Brasil
}

\section{ABSTRACT}

Objective: To identify and analyze the weaknesses of the nurse's practice in meeting spontaneous demands in primary care units in the city of Rio de Janeiro.

Method: Qualitative study carried out in Rio de Janeiro, in 2016, with 20 nurses recruited unintentionally. The focus group and simple observation were applied, and data were subjected to thematic content analysis.

Results: The spontaneous demand service causes tensions and work overload. Nurses and community health agents are primarily responsible for organizing access.

Final considerations: There was a lack of understanding of the practice of spontaneous demand as part of care management, in addition to a polysemy related to the term. While for some, welcoming practices means greater autonomy, incorporating a larger scope of actions related to care and expanding their clinical practice; for others, they represent a stage that precedes medical consultation and a disorganizing element of care.

Keywords: Health knowledge, attitudes, practice. Health services needs and demand. Primary health care.

\section{RESUMO}

Objetivo: Analisar as fragilidades da prática do enfermeiro no atendimento à demanda espontânea nas unidades de atenção primária do município do Rio de Janeiro.

Método: Estudo qualitativo realizado no Rio de Janeiro, em 2016, com 20 enfermeiros recrutados não intencionalmente. Aplicou-se o grupo focal e a observação simples, e os dados foram submetidos à análise temática de conteúdo.

Resultados: 0 atendimento por demanda espontânea provoca tensões e sobrecarga no trabalho. 0 enfermeiro e 0 agente comunitário de saúde são os principais responsáveis pela organização do acesso.

Considerações finais: Constatou-se a incompreensão da prática da demanda espontânea como integrante da gestão do cuidado, além da polissemia relacionada ao termo. Enquanto para al guns as práticas de acolhimento significam maior autonomia, incorporando um escopo maior de ações referentes ao atendimento e ampliando a sua prática clínica; para outros, representam uma etapa que antecede a consulta médica e um elemento desorganizador da assistência.

Palavras-chave: Conhecimentos, atitudes e práticas em saúde. Necessidades e demandas de serviços de saúde. Atenção primária à saúde.

\section{RESUMEN}

Objetivo: Identificar y analizar las debilidades de la práctica de la enfermera para atender la demanda espontánea en las unidades de atención primaria de la ciudad de Rio de Janeiro.

Método: Estudio cualitativo realizado en Rio de Janeiro, en 2016, con 20 enfermeras reclutadas de manera no intencional. Se aplicó el grupo focal y la observación simple, y los datos fueron sometidos a análisis de contenido temático.

Resultados: El servicio de demanda espontánea genera tensiones y sobrecarga de trabajo. La enfermera y el agente de salud de la comunidad son los principales responsables de organizar el acceso.

Consideraciones finales: Existía una falta de comprensión de la práctica de la demanda espontánea como parte de la gestión del cuidado, además de una polisemia relacionada con el término. Mientras que para algunos las prácticas de acogida significan una mayor autonomía, incorporando un mayor abanico de acciones relacionadas con el cuidado y ampliando su práctica clínica; para otros, representan una etapa que precede a la consulta médica y un elemento desorganizador de la atención.

Palabras clave: Conocimiento, actitudes y práctica en salud. Necesidades y demandas de servicios de salud. Atención primaria de salud. 


\section{口INTRODUCTION}

In Brazil, the standardization and reorientation of nurses' practices in Primary Health Care (PHC) were carried out by the Ministry of Health, through the National Primary Care Policy (1), combined with other health policies such as the Policy of Welcoming to Spontaneous Demand and the National Program for Improving Primary Care Access and Quality (PMAQAB) $)^{(2-3)}$. These policies redefined the health care model, as they induced changes in the nurses' work process and in the organization of the health teams' work process.

In the city of Rio de Janeiro, PHC is based on the care model composed of Family Clinics, which carry out actions for health promotion, prevention and early diagnosis of diseases. There was an increase in the care coverage carried out by the Family Health Strategy (ESF), from 3.5\% in 2009 to $70 \%$ in $2017^{(4)}$. The proposals of the municipal management included the valuation of the family physician as a priority specialty in the organization of the work process, in addition to the strong induction for increased access and resoluteness of health teams, through normative documents, adoption of new indicators and pay-for-performance ${ }^{(5)}$.

From the perspective of expanding the entry points to the health system, as well as the qualification of the responses offered to the population by PHC teams, under the logic of the ESF model, nurses were asked to modify their practice and expand their scope of clinical performance in meeting spontaneous demands from users ${ }^{(5)}$.

This change in PHC practices in the municipality imposed new challenges on nurses, bringing together the municipal management and the Regional Nursing Council, Rio de Janeiro section. The partnership was consolidated and, in 2012, the Primary Care Nursing Protocol of the Municipality of Rio de Janeiro was published. The Protocol established norms and authorized nurses to monitor users in chronic health conditions, as well as allowing some actions related to acute illnesses ${ }^{(5)}$.

It is known that the expansion of clinical nursing practice can impact the efficiency of care and help to strengthen the user-nurse reference, providing greater credibility with the population served. It is noteworthy that the increase in the clinical autonomy of nurses does not require the replacement of physicians by nurses. A care model shared by nurses and family physicians tends to facilitate access to services and qualify care within the specificity of each professional nucleus(6).

The importance of cooperation between the categories is also highlighted, considering comprehensive care.
Interdisciplinary collaboration aims to increase the scope of the team's work to solve the health problems of the population assisted. Therefore, it is essential that this practice is carried out by all team members and not only by physicians and nurses ${ }^{(1,7)}$.

However, given the needs of the population, ESF nurses may be the only professionals capable of meeting spontaneous demands in PHC. Such demands would make it difficult for nurses to carry out other functions that are exclusively performed by them. The factors that contribute to this phenomenon include: 1) the frequent lack of physicians in healthcare teams; 2 ) the lack of professional training to meet clinical demands; and 3) high care pressure with work overload ${ }^{(8-9)}$.

Nurses and physicians from Primary Health Care Units (UAPS) meet spontaneous demands and sometimes the boundaries between the responsibilities and functions of each professional nucleus are unclear, which leads to prioritization and/or scheduling of medical appointments and procedures ${ }^{(6)}$. One explanation for this situation is the shortage and turnover of physicians in PHC. However, it is also necessary to reflect on the need to ensure the key role of the subjects involved in health production; reorganize services based on the problematization of work processes and expand democratic spaces for discussion, sensitive listening and collective decisions ${ }^{(8)}$.

Nurses, who are responsible for a significant portion of care coordination, often accumulate functions, becoming overloaded ${ }^{(9)}$. It should be noted that the entire PHC team and not only nurses are responsible for such coordination, which is necessary for health production, socialization between the various knowledge and practices, in order to ensure a more effective intervention in complex situations in the registration area $^{(7)}$.

However, uncertainties in meeting customers' demands are not only aggravated by the lack of physicians, they are also related to a service proposal that permeates the work process, in which all health professionals are supposed to collaborate to meet the demands and needs of users ${ }^{(7-8)}$.

The above described conditions can subject health professionals to excessive pressure, overload and suffering, which favor practices focused on "treat and street" without a contact for a sensitive listening of users. These factors can lead workers to adopt defensive postures regarding the health needs of users ${ }^{(9)}$, which does not favor a qualified assessment based on the health determinants and conditions of the population ${ }^{(7)}$.

Then, the following guiding question was defined for the study: What are the weaknesses of nurses'practice in meeting spontaneous demands in Primary Care Units? Looking at the 
transformation proposed by $\mathrm{PHC}$, the present study aims to analyze the weaknesses of nursing practice in meeting spontaneous demands in primary care units in the city of Rio de Janeiro.

\section{$\square$ METHOD}

This is an exploratory study with a qualitative approach. The study setting was composed of primary health care units (UAPS) with family health strategies (ESF), located in the West Zone of the city of Rio de Janeiro/RJ, inserted in Program Area 5.3. This is one of 10 administrative areas in the health sector in the city of Rio de Janeiro, according to the system of distribution of care services and levels. The research is part of the project entitled Nurses'Practices and Knowledge in Primary Care: dialogues with popular education in its theoretical-methodological perspectives.

One nurse from each PHC unit was selected in Program Area 5.3 in this study, totaling 25 nurses. Program Area 5.3 has 25 UAPS, of which 15 are Type A (Family Clinics), that is, they cover the entire territory served by ESF teams, and 10 are Type B (Municipal Health Centers), with part of the territory covered by ESF teams.

Of the 25 selected nurses, 20 participated in the study. Participants were recruited by random sampling, according to the following inclusion criteria: nurse who is part of a complete ESF team that includes all professional occupations; who has been working with a team for at least six months; nurse in the PHC unit team with the largest number of families per team. Nurses temporarily replaced by another professional; who were on sick leave/vacation; or away from work during the period of data collection were excluded from the study.

Data were collected from May to July 2018, through simple observation and focus group (FG) techniques ${ }^{(10)}$. The nurses agreed to be observed during a four-hour work shift. Six nurses were monitored, totaling 68 observations of nursing appointments to individuals (by spontaneous demand), with an average duration of 20 minutes per appointment. The material was collected and systematized through a field diary recorded in a field notebook.

Regarding the Focus Group (FG) activity, the 20 nurses were previously invited by telephone contact, and the place and date were established, so that this activity would not interfere with the participants' work routine. Two groups with 10 participants were formed, so that they could express their opinions and points of view on the subject of the study. The FG activities were carried out in the meeting room of one of the PHC units where only the researcher and the respondents were present.

The two FGs were audio-recorded, and the debate was guided by questions with themes about the object of study, namely: What do you consider spontaneous/free/acute complaints in your daily practices as PHC nurses? What are the nurses'practices in attending to spontaneous demands? What is the relationship between the practices aimed at meeting spontaneous demands and your other functions? Is there any relationship?

The two groups lasted an average of 50 minutes, and the activities were carried out at the headquarters of the District Health Council in Program Area 5.3. During the analysis of the material collected in the $\mathrm{FG}$, the research team checked data saturation ${ }^{(10)}$ to avoid repetition. No additional meetings with the participants were necessary.

In the pre-analysis stage, the recording of the content of the focus groups was transcribed and analyzed with the use of Bardin's content analysis technique ${ }^{(11)}$. In the material exploration stage, the object of study and the research objectives were resumed, and the coding of Registration Units (RU) began. In the processing of the results, the identified registration units (RU) were then grouped, resulting in Units of Meaning (US) or themes ${ }^{(11)}$.

After mapping and quantification of the RU, three categories emerged: Visions and meanings of professional practice in meeting spontaneous demands; Limits of professional practice in meeting spontaneous demands; Practice transformations: access and assistance to spontaneous demands. However, this article explored only one of the categories: Limits of professional practice in meeting spontaneous demands.

The nurses were codified with the acronym FG 1 or 2 , according to their FG group followed by abbreviation "Nur" (for nurse) and a sequential Arabic number, according to the inclusion order.

All participants signed the Free and Informed Consent form, and all the guidelines and regulatory standards for research with human beings described in Resolution No. $466 / 12$ of the National Health Council were observed. The study was approved by the Research Ethics Committee of Universidade do Estado do Rio de Janeiro, under Protocol No. 2481797, and by Secretaria Municipal de Saúde of Rio de Janeiro, under Protocol No. 2601693. 


\section{RESULTS}

Of the 20 nurses who participated in the study, $95 \%$ were women, with a mean age of 33 years. Most participants have been working in the same unit and team since they joined the PS, and have been working on average for five years in the city of Rio de Janeiro.

Regarding professional training, $85 \%$ of the participants had graduated in the last 10 years; $70 \%$ had graduated from private schools; $90 \%$ had lato sensu specialization in the PHC area, with $72 \%$ of these courses in private institutions; $6 \%$ obtained a residency in Family Health; and 17\%, in addition to lato sensu specialization, had stricto sensu master's degree.

In the processing of the data collected through the FG, the category named "Limits of professional practice in meeting spontaneous demands"emerged, which generated 248 $R U$, representing $39.61 \%$ of the total $R U$ in the study. The results collected during the observations, through the field diary, supported the researchers during the analysis and implementation of the Focus Groups.

This category identified several situations related to spontaneous demands in PHC that impact the service, and which involve: a longer waiting time for users; assistance targeted to complaints-conduct; impact on the organization of the service; little multidisciplinary participation; coordination of care; overload of nurses in PHC, among others.

Respondents said that the flow of non-scheduled users (spontaneous demand) is a disorganizing factor in the work process of PHC:

\section{[...] spontaneous demand has an impact on the organi- zation of the work process (FG1-Nur 8). \\ [...] if nursed assist all non-scheduled users (spontaneous demand), patients will always request assistance via spontaneous demand (FG1-Nur 12).}

However, regarding access by spontaneous demand, the health professionals expressed dissenting views, as shown in the following statement:

\section{[...] Meeting a spontaneous demand is an opportunity for a nurse to provide integral care [...] (GF2-Nur 4).}

In the focus groups ( $F G$ ), the nurses expressed different opinions about the role of the Community Health Agent $(\mathrm{CHA})$ in the welcoming/first listening model of primary care Family Clinics. A group of nurses thinks that $\mathrm{CHA}$ should be the first professionals to welcome users when they arrive at the health unit. Other nurses do not agree, as they understand that $\mathrm{CHA}$ are not sufficiently trained to carry out the first listening, risk assessment and establishment of the priority order of care.

Spontaneous demand occurs when the CHA is unable to assist the users and sends them to the nurse (GF1-Nur 5).

The CHA does not have specific training to assist the users (GF1-Nurse 1).

The CHA is not responsible for classifying the patient's risk (GF1-Nur 12).

There were several arrangements in the organization of the entry points of the units observed, and a common characteristic was the fact that all users were heard by a $\mathrm{CHA}$ or by the nurse and then the type of care that the user would receive was determined.

Regarding the work process related to spontaneous demand, the respondents explained that sometimes slow flows and work overload make it difficult for users to access health services, especially when there is an increase in the registered population and there is no implementation of new ESF teams by municipal management to meet these needs. They also reported the impact on the organization of access due to the lack of professionals in the minimum composition of the teams (nurse, physician, nursing technician and CHA), as explained in the statements below:

The registered population is growing, but the number of professionals is insufficient to meet the population's demand (GF1-Nur 10).

The lack of physicians in the teams impacts the organization of spontaneous demand (GF1-Nur 10).

If the teams were complete, the first contact with users for a sensitive listening/and reception in the physician's office would be possible (GF1-Nur 03).

Another relevant aspect was the organization of access in the PHC units. It should be stressed that in certain cases, some PHC principles, especially longitudinality and coordination of care, can be impacted when the first and sensitive listening of users and care are not carried out by the reference team.

Users are welcomed by a nurse for all teams (GF1-Nur 5).

The welcoming/first sensitive listening of users of the unit is done by dividing the number of patients (by order of arrival) by the total number of nurses in the unit present in the unit's reception (GF1-Nur 12).

It was also found that the acceptance of spontaneous demand by nurses, according to the users, is a barrier to 
medical access, demonstrating a model of medical-centered care. In the statement below, there are some questions about the real purpose of welcoming/reception: this can be perceived as a way of benefiting the manager by reducing the need to hire physicians, or as a benefit for the medical occupation, by reducing their presence in PHC units. Such interpretations disregard the real purpose of welcoming as an environment for organizing services and work processes.

The patient perceives the nurse responsible for the welcoming as someone who makes access to the physician more difficult (FG1-Nur 11).

It should be noted that the lack of normative documents, such as clinical care protocols for the practice of nurses in assisting spontaneous demand, can affect the consolidation of professionals'actions in PHC and the strengthening of their professional identity in relation to the population assisted.

It is essential to identify the roles and responsibilities of each team member in meeting spontaneous demand (GF1-Nur 11).

The respondents revealed the daily tensions in the organization of access and the difficulty of cooperation of medical colleagues in the organization and support activities, which evokes reflection on the sharing of knowledge and interdisciplinary practices and the imperative need to act in team, especially in PHC.

Physicians are reluctant to welcome users at the PHC unit reception; I only once saw a doctor welcome users in a PHC unit during a strike (GF2-Nur 2).

There, the doctor and the nurse can do a lot.. Our team meeting is more productive, as we remember patients on spontaneous demand. The patient with leprosy came yesterday and we are organizing longitudinal care (FG1-Nur 9).

During the FG activity, the views of health professionals about the manner and attitudes of users who seek the health unit were clear. Participants reported that the users were very straightforward and had doubts about when to access the unit through spontaneous or scheduled demand.

Users are very straightforward and direct: they want medication and exams (FG1-Nur 6).

Users still have many doubts regarding what is a spontaneous demand (GF1-Nur 9)
The statements portray the perception of the nurses in PHC units regarding the municipal management, and the ESF team itself, who are unable to guarantee information and access to the services offered in the Family Clinics in the city of Rio de Janeiro that were investigated.

Thus, the existence of a dichotomous logic between spontaneous and scheduled demand is clear, as teams routinely organize their activities according to the risk of illness, contrary to clinical practice focused on users' needs.

\section{DISCUSSION}

PHC, proposed by Starfield ${ }^{(12)}$, can be assessed by the existence of four essential attributes: individual's first contact (access) with the health system, longitudinality, integrality, coordination of care, and three derived attributes: family orientation, community orientation and cultural competence.

The process of assistance to spontaneous demand should seek to assess the need for immediate care; provide or facilitate first care; identify individual and collective vulnerabilities; classify risk to define care priorities; organize the physical disposition of patients in the service; and refer users to care according to their classification ${ }^{(13)}$.

In this study, although nurses referred to spontaneous demand as a powerful strategy to achieve the attributes of $\mathrm{PHC}$, they refute this idea when they envision a work process centered on programmatic actions and sometimes have difficulty understanding their role in the organization of access.

Historically, in the traditional model of care in Brazil (traditional health care centers), programmed actions, guided by risk groups, have been prioritized, and there is little space in the organization of access for users with acute pain ${ }^{(14)}$. A dichotomy was created between the types of care - spontaneous demand and scheduled demand - which, at times, generates conflicts in the health teams regarding the organization of access to care in the PHC.

The nurses' statements also showed that spontaneous demand is considered an opportunity to contact users who seek the primary care unit, to put into practice the essential attributes of PHC. By valuing this encounter with the users, nurses enhance the establishment and maintenance of a bond with the users and expand the integrality of health care, creating conditions to overcome old dichotomies in the field of Public Health and PHC.

At the same time, the participants understand spontaneous demand as a disorganizing factor in the work process in the ESF. This understanding may be linked not only to the difficulty in perceiving spontaneous demand as part of the process of coordinating care supported by the pillars of 
information, clinic and administration/organization, but also to care "pressure", arising from the high volume of spontaneous demand that causes work overload. There is also lack of physicians in the minimum team, tensions related to the organization of access and a lack of medical cooperation in care.

Studies ${ }^{(8-9,15)}$ corroborate the above findings, stating that the low population coverage, the high number of registered users, the poor quality care, the lack of CHA, the ineffectiveness of management, the scarcity of scheduled actions and the high demand for spontaneous demands are factors that limit the population's access and complicate care management by the ESF teams ${ }^{(15)}$.

In most cases, the care provided in the ESF results from spontaneous demand, based on the individual needs of users, since they generally want medical appointments, referrals to specialties and distribution of medications. It should also be mentioned that users generally seek assistance to treat their illnesses ${ }^{(15)}$, as they perceive assistance as a way to meet their immediate needs, which are still strongly centered on the biomedical model ${ }^{(14)}$. Thus, users' perception that the acceptance of spontaneous demand by nurses is a barrier that prevents their access to medical appointments is justified.

These aspects reveal the need to create dialogic spaces with users, in order to clarify the attributes of PHC, as well as address the organization and access to services, reinforcing the importance of health promotion and disease prevention.

Regarding the limitation of the user's disconnection from the team, it is essential that the reference team in PHC makes the first contact and sensitive listening, evaluates and refers the user to care as needed. It is believed that valuing the subjective and relational dimension of care strengthens the bond between nurses and users and facilitates the joint identification of problems and solutions, as it brings professionals closer to the users'life context, thus improving users' trust and satisfaction with health professionals and adherence to the care plan ${ }^{(16)}$. Thus, team's bond and longitudinality in relation to the registered population is a key factor for achieving effectiveness and trust, in addition to enhancing the coordination of user care ${ }^{(7)}$.

During the FGs and field observations, some nurses stated that community health agents ( $\mathrm{CHA}$ ) are supposed welcome the users who arrive at the unit, while others said that the $\mathrm{CHA}$ are not trained for this type of activity.

In the reorganization of the PHC units in the municipality of Rio de Janeiro, the teams were inserted into a standardized work process model, in which one of the roles of the CHA is to receive and make the first contact/sensitive listening to the users in the respective coverage area, devoting an average of three shifts in the week to this activity ${ }^{(4)}$. Thus, it was found that access to PHC units begins with the first sensitive listening/contact of $\mathrm{CHA}$ and the nurse with all users who seek care.

It is known that the CHA is an important player in the health team and in the assistance to users, and, among other things, this professional aims to recognize the social risks of the assisted population. Some authors ${ }^{(17)}$ claim that there is a growing formalization of the presence of $\mathrm{CHAs}$ in internal activities in health units, and this professional is often responsible for assisting users, to the detriment of home visits in the territory.

When assistance of spontaneous demand is understood by the multidisciplinary team as attitude, posture and health technology, access of users to health services can be facilitated. Then, resources are optimized and the response to individual demands and, simultaneously, to collective population needs, is extended ${ }^{(1,4)}$. as well as the sharing of the workload with the other team members.

However, there is a challenge to be faced for the consolidation of the care model in the ESF, whose centrality of health actions tends to meet the needs of the subjects, expanding the therapeutic possibilities. It is known that for the consolidation of PHC as the coordinator and organizer of care in the health care network, users must have easy access and in a timely manner when they need it, in order to establish the legitimacy of the health unit for the registered population ${ }^{(3,18)}$.

Thus, it was found that the statements of the participants address again the dichotomy between individual clinic and extended clinic based on the epidemiological context. It is understood that the individual clinic follows a logic centered on the health professional and on procedures, while the extended clinic contributes to an approach to illness and suffering, as it is a theoretical and practical instrument that contemplates the uniqueness of the subject and the complexity of the health-disease process ${ }^{(7)}$.

PHC must guarantee the provision of sequential and complementary care between the levels of care ${ }^{(18)}$, such as a clinical coordination, with spontaneous demand being one of the moments of identification of unique care based on the health needs of the subjects and their families ${ }^{(19)}$. Therefore, the extended clinic must be the ethical-political imperative of the organization of services and professional intervention ${ }^{(20)}$.

Thus, the entire team needs to rethink the organization of the work process and access. One of the necessary steps to achieve this intent is to replace the actions centered on the procedures and health professionals with a work process based on the users'needs, thus strengthening the integrality of care in health actions ${ }^{(20)}$. 
It should be noted that despite the existence of guiding policies aimed at changing the care model, there are still bureaucratically organized health establishments in Brazil, in which the services provided are organized in strict schedules, centered on medical appointments and with limited provision of care ${ }^{(13,17)}$.

In summary, support and continuing education strategies are needed to improve assistance in primary care teams, which can transform everyday situations into sources of pedagogical demands, in order to ensure effective care, as well as qualify the clinical approach of cases and flows of the health care network ${ }^{(12)}$.

In this context, although nurses have documents that regulate assistance to spontaneous demand, these were created based on the logic of the multidisciplinary team. However, the instruments of the nursing profession must be used to provide adequate guidance to nursing appointments, with specific approaches of the Systematization of Nursing Care (SNC), so that these instruments are recognized, improved and established as professional practice.

Regardless of the form of access to the demand (spontaneous or scheduled, the appointment must be centered on the user's needs and sensitive to the psychological, family, community and social context of the subjects involved, respecting their autonomy and favoring self-care. Thus, the nursing process is carried out with an adequate theoretical foundation in order to ensure a high-quality care.

In the practice of nurses, there was a misunderstanding that spontaneous demand is part of care management; weakness in the use of the nursing process; as well as an important polysemy related to the concepts of spontaneous demand, concepts that created paradoxes such as the increase in autonomy, with the incorporation and expansion of clinical practice in PHC.

\section{GINAL CONSIDERATIONS}

The contexts and weaknesses identified by nurses for the operationalization of spontaneous demand are related to: dichotomy between scheduled and spontaneous demands; fragmented organization of access; user's disengagement from his reference team; organization of the work process of the teams centered on medical appointments; little understanding of PHC as an organizer of the health care network; need to strengthen the extended clinic in the work of the interdisciplinary team, and inconsistency in the use of the nursing process.

A limitation of this study was the non-inclusion of other Program Areas in the city of Rio de Janeiro. Therefore, it is suggested that this study be replicated with PHC nurses from these other areas.

The contribution of this study lies in the proposition of a reflection aimed at deconstructing the dichotomy between scheduled demand and spontaneous demand, in order to favor an organization of assistance as an instrument of health technology, based on the health needs of users, with a guarantee of delivery of effective care by the entire health team and not only by nurses.

Furthermore, when nurses assist spontaneous demand, through the expansion of clinical practice and application of the SNC, there can be a better organization of the work process, consolidation of professional practice, clinical reasoning, qualification of care, in addition to providing effective access of users to services according to their health needs.

Therefore, it is urgent to improve the clinical training of nurses, from their academic training to the processes of continuing education in health services, and especially the recognition of spontaneous demand as an operational instrument of the work process and the qualification of the services provided by the ESF.

\section{REFERENCES}

1. Ministério da Saúde (BR). Portaria n. 2.436, de 21 de setembro de 2017. Aprova a Política Nacional de Atenção Básica, estabelecendo a revisão de diretrizes para a organização da Atenção Básica, no âmbito do SUS. Diário Oficial da União. 2017 set 12 [cited 2020 Dec 14];154(183 Seção 1):68-76. Available from: https://pesquisa.in.gov.br/imprensa/jsp/visualiza/index. jsp?jornal $=1 \&$ data $=22 / 09 / 2017$ \&pagina $=68$

2. Ministério da Saúde (BR). Secretaria de Atenção à Saúde. Departamento de Atenção Básica. Acolhimento a demanda espontânea. Brasília, DF: Ministério da Saúde; 2013 [cited 2020 Dec 14]. v. 1. Available from: http://bvsms.saude.gov.br/bvs/ publicacoes/acolhimento_demanda_espontanea_cab28v1.pdf

3. Ministério da Saúde (BR). Portaria n. 1.645, de 2 de outubro de 2015. Dispõe sobre o Programa Nacional de Melhoria do Acesso e da Qualidade da Atenção Básica (PMAQ-AB). Diário Oficial União. 2015 out 5 [cited 2020 Dec 14];152(190 Seção 1): 668-9. Available from: https://pesquisa.in.gov.br/imprensa/jsp/visualiza/ index.jsp?data $=05 / 10 / 2015 \&$ jornal $=1$ \&pagina $=668 \&$ totalArquivos $=908$

4. Pinto LF, Giovanella L. The Family Health Strategy: expanding access and reducing hospitalizations due to ambulatory care sensitive conditions (ACSC). Ciênc Saúde Coletiva. 2018;23(6):1903-13. doi: http://doi. org/10.1590/1413-81232018236.05592018

5. Prefeitura da Cidade do Rio de Janeiro (BR). Secretaria Municipal de Saúde. Subsecretaria de Atenção Primária, Vigilância e Promoção da Saúde. Superintendência de Atenção Primária. Enfermagem no cuidado dos ciclos de vida no contexto da atenção primária à saúde [Internet]. Rio de Janeiro; 2017 [cited 2020 Dec 14]. Available from: https://issuu.com/asasrio/docs/ protocoloenfermagem_ciclosdevida_or

6. Salci MA, Meirelles BHS, Silva DMGV. Primary care for diabetes mellitus patients from the perspective of the care model for chronic conditions. Rev Latino-Am Enfermagem. 2017;25:e2882. doi: http://doi.org/10.1590/1518-8345.1474.2882 
7. Campos GWS. [Public health and collective health: field and core area for knowledge and practice]. Ciênc Saúde Coletiva. 2000;5(2):219-30. Portuguese. doi: https:// doi.org/10.1590/S1413-81232000000200002

8. Mitre SM, Andrade EIG, Cotta RMM. Avanços e desafios do acolhimento na operacionalização e qualificação do Sistema Único de Saúde na Atenção Primária: um resgate da produção bibliográfica do Brasil. Ciênc Saúde Coletiva. 2012;17(8):2071-85. doi:https://doi.org/10.1590/S1413-81232012000800018

9. Freitas PH, Beck CLC, Viero V, Fernandes MNS, Machado KL. Defensive strategies used by nurses in the Estratégia Saúde da Família to cope with distress. Texto Contexto Enferm. 2016;25(4):e3050014. doi: http://doi. org/10.1590/0104-07072016003050014

10. Gil AC. Métodos e técnicas de pesquisa social. 7. ed. São Paulo: Atlas; 2019.

11. Bardin L. Análise de conteúdo. São Paulo: Edições 70; 2015.

12. Starfield B. Atenção primária: equilíbrio entre necessidades de saúde, serviços e tecnologia. Brasília, DF: Unesco; Ministério da Saúde; 2002 [cited 2020 Dec 14]. Available from: https://repositorio.observatoriodocuidado. org/bitstream/handle/handle/2326/livro_starfield_atencao_primaria. pdf? sequence $=1 \&$ isAllowed $=y$

13. Ministério da Saúde. Secretaria de Atenção à Saúde. Departamento de Atenção Básica. Acolhimento a demanda espontânea: queixas mais comuns na Atenção Básica. Brasilia, DF: Ministério da Saúde; 2013 [cited 2020 Dec 14]. v. 2. Available from: http://bvsms.saude.gov.br/bvs/publicacoes/acolhimento_demanda_ espontanea_queixas_comuns_cab28v2.pdf
14. Tesser CD, Norman AH. Repensando 0 acesso ao cuidado na Estratégia Saúde da Família. Saúde Soc. 2014;23(3):869-83. doi: https://doi.org/10.1590/ S0104-12902014000300011

15. Chávez GM, Viegas SMF, Roquini GR, Santos TR. Access, accessibility, and demand at the Family Health Strategy. Esc Anna Nery. 2020;24(4):e20190331. doi: https:// doi.org/10.1590/2177-9465-ean-2019-0331

16. Santos FPA, Acioli S, Rodrigues VP, Machado JC, Souza MS, Couto TA. Nurse care practices in the Family Health Strategy. Rev Bras Enferm. 2016;69(6):1060-7. doi: https://doi.org/10.1590/0034-7167-2016-0273

17. Morosini MV, Fonseca AF. Configurações do trabalho dos agentes comunitários na Atenção Primária à Saúde: entre normas e práticas. In: Mendonça MH, Matta GC, Gondim R, Giovanella L, organizadores. Atenção Primária à Saúde no Brasil: conceitos, práticas e pesquisa. Rio de Janeiro: Fiocruz; 2018. p. 369-405.

18. Bousquat A, Giovanella L, Campos EMS, Almeida PF, Martins CL, Mota PHS, et al. Primary health care and the coordination of care in health regions: managers 'and users' perspective. Ciênc Saúde Coletiva. 2017;22(4):1141-54. doi: http:// doi.org/10.1590/1413-81232017224.28632016

19. Leoneza I, Paz EPA, Guimarães RM, Castro AA. Access to family health unit from the hypertensive's perspective. Rev Enferm UERJ. 2017;25:e14442. doi: https:// doi.org/10.12957/reuerj.2017.14442

20. Barbiani R, Nora CRD, Schaefer R. Nursing practices in the primary health care context: a scoping review. Rev Latino-Am Enfermagem. 2016;24:e2721. doi: http://doi.org/10.1590/1518-8345.0880.2721 


\section{- Authorship contribution:}

Gláucia Bohusch - conceptualization, data curation, formal analysis, investigation, methodology, project management, resources, validation, writing- original draft, writing - review and editing. Sonia Acioli - conceptualization, data curation, formal analysis, investigation, methodology, project management, resources, supervision, validation, writing - original draft, writing - review and editing. Ricardo de Mattos Russo Rafael - validation, visualization, writing- original draft, writing - review and editing.

Alex Simões de Mello - visualization, writing- original draft, writing - review and e editing.

Juliana Roza - visualization, writing- original draft, writing - review and editing.

Halene Cristina de Armada e Silva - visualization, writing - original draft, writing - review and editing.

The authors declare that there is no conflict of interest.

\section{- Corresponding author:}

Gláucia Bohusch

E-mail: glauciabohusch@gmail.com

\section{Associate editor:}

Carlise Rigon Dalla Nora 